\title{
ANALIZA EKONOMSKIH ASPEKATA PRIMENE 5G TEHNOLOGIJE
}

\author{
Saša Stamenković1, \\ Marina Marjanović-Jakovljević
}

\author{
${ }^{1}$ Poslovni fakultet, \\ Univerzitet Singidunum, \\ Beograd, Srbija \\ ${ }^{2}$ Tehnički fakultet, \\ Univerzitet Singidunum, \\ Beograd, Srbija
}

\begin{abstract}
Rezime:
$5 \mathrm{G}$ je sledeći korak u evoluciji mobilne tehnologije. U odnosu na prethodne generacije mobilnih tehnologija, 5G se bitno razlikuje po malom kašnjenju (near zero latency) i većim brzinama prenosa, reda 1-10 Gbps. Uticaj 5G tehnologije na ekonomiju ima jednostavan tok - investira se u razvoj i implementaciju 5G mreže, investicije kreiraju nova radna mesta, a sve to zajedno povećava BDP (bruto društveni proizvod). Nećemo zaboraviti ni benefite od nove tehnologije, rast produktivnosti i efikasnosti usled sveprisutnog i ultrabrzog broadbanda, uštede u vremenu i resursima zahvaljujući primeni naprednih $5 \mathrm{G}$ servisa. $5 \mathrm{G}$ tehnologija će u budućnosti biti baza za inovacije u privredi i industriji. $U$ ovom radu predstavljena je analiza uticaja primene $5 \mathrm{G}$ tehnologije na ekonomiju.
\end{abstract}

Ključne reči: spektar, IoT, Cloud, 5G servisi, MIMO.

\section{UVOD}

Tokom istorije i tehnološke evolucije, mnoge tehnologije našle su najširu primenu u više oblasti ljudskog rada i života. Najočigledniji primeri su otkriće parne mašine, železnice, automobila, električne energije, telefona, interneta. Svojom primenom ova otkrića promenila su poslovne procese, životne navike, produktivnost ljudi i mašina, donela čovečanstvu veliku ekonomsku korist, a ljudima bolji životni standard. 5G tehnologija ima izglede da postane novi katalizator produktivnosti i povećane ekonomske aktivnosti u mnogim granama privrede. Očekuje se da će 5G tehnologija i mreža imati pozitivan uticaj na globalni ekonomski održivi rast i razvoj. Ona će omogućiti sveopštu povezanost (umreženo društvo, Networked Society). Potencijal 5G tehnologije kroz mnogostruke načine korišćenja (use case) je ogroman. Mobilna tehnologija je prošla put od platformi koje su služile samo za povezivanje ljudi (2G, $3 \mathrm{G}$ ) do platformi koje ljude povezuju i sa mašinama (4G). $\mathrm{U}$ odnosu na $3 \mathrm{G}$ tehnologiju, $4 \mathrm{G}$ je unapredila kapacitet mreže, brzine prenosa, iskorišćenje spektra i smanjila kašnjenje. 5G mreža podrazumeva sveprisutnu (ubiquitous) ultrabrzu broadband infrastrukturu, koja će podstaći tražnju i potrebe korisnika i uticati na transformaciju poslovnih procesa u svim granama privrede (tzv. digitalna transformacija). 5G će transformisati ne samo personalne komunikacije, već i čitavu privredu i ekonomiju. Iako $4 \mathrm{G}$ generacija mobilnih tehnologija
Correspondence:

Saša Stamenković

e-mail:

sstamen@beotel.rs 
u mnogim zemljama još uvek nije implementirana, svet se već okreće novoj, 5G. Japan i Južna Koreja su među svetskim liderima u primeni žične broadband tehnologije, a sad žele primat i u bežičnoj tehnologiji. Južna Koreja priprema 5G mrežu za Zimske olimpijske igre 2018. a Japan za Letnje 2020. godine. Početak šire komercijalne primene 5G tehnologije očekuje se nakon 2020. godine. Razvoj 5G tehnologije zahteva novi pristup u regulativi i politici u oblasti javne bezbednosti, raspodele spektra, cyber bezbednosti, privatnosti, zdravstva, obrazovanja, javne infrastrukture. Kreatori politike i regulative moraju voditi računa da ne sputavaju inovacije i investicije koje su presudne za razvoj $5 \mathrm{G}$.

\section{KARAKTERISTIKE 5G TEHNOLOGIJE I MREZE}

Glavne prednosti uvođenja $5 \mathrm{G}$ su niži troškovi, veći kvalitet usluga, visoka raspoloživost mreže. Nema svrhe za posebne mreže za sve sisteme, nego se koristi tzv. network slicing tehnika. Network slicing je način da više mreža radi na istoj infrastrukturi. Osigurano je dinamičko upravljanje i kontrola saobraćaja. 5G će podržati aplikacije koje zahtevaju visoku pouzdanost, raspoloživost i bezbednost i ultranisko kašnjenje u prenosu informacija. To će omogućiti podršku autonomnim vozilima, daljinskom obavljanju složenih radnji i operacija i daljinskom upravljanju opremom (npr. telehealth).

Mogućnosti 5G mreže i tehnologije su sledeće [1]:

- Bitske brzine za korisnike 1-10 Gbps;

- Ultranisko kašnjenje end-2-end reda 1-5 ms;

- 1000x veći bandwith po jedinici pokrivene povšine;

- Mogućnost konektovanja 10-100x više uređaja;

- Mogućnost konekcije u pokretu pri brzini kretanja do $500 \mathrm{~km} / \mathrm{h}$

- Pokrivenost $100 \%$, raspoloživost $99,999 \%$;

- Smanjenje potrošnje energije u mreži za 90\%;

- Produženi vek trajanja baterije do 10 godina za uređaje sa niskom potrošnjom.

Tehničke mogućnosti i karakteristike 5G tehnologije znatno se razlikuju od onih prethodne generacije mobilnih tehnologija (Slika 1). 5G tehnologija može da koristi i licencirani i nelicencirani spektar, može se koristiti i u javnim i u privatnim mrežama, što joj otvara mogućnost široke primene $u$ industriji. Različiti načini primene na različitim uređajima imaju presudan ekonomski uticaj. 5G infrastuktura mnogo je efikasnija u odnosu na prethodne generacije mobilnih komunikacija. To se odnosi na hardver, spektralnu efikasnost, energetsku efikasnost, pojednostavljenu integraciju, brže kreiranje servisa. Sve to znači i niže troškove svih učesnika u poslovnom procesu. Energetska efikasnost je veoma važna za očuvanje životne sredine i održanja klimatskih uslova. Manja potrošnja personalnih uređaja znači i duže trajanje baterije, što je veoma bitno za primenu koncepta Internet of Things (IoT).

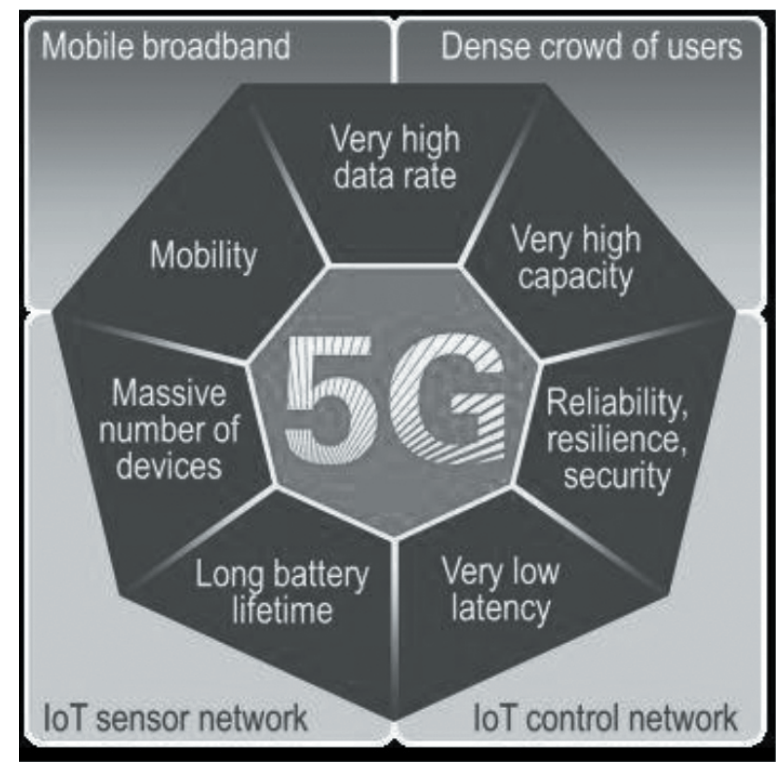

Slika 1. Karakteristike 5G tehnologije (www.rohde-schwarz.com).

5G mreža treba da bude ultrabrza, manje energetski zahtevna i softverski upravljana. Hardver 5G mreže je uglavnom virtuelizovan tj. zamenjen softverom $i$ jednostavan za rekonfiguisanje. 5G infrastruktura koristi koncept Cloud computing-a i integriše networking, storage $\mathrm{i}$ computing. Resursi su distribuirani i optimizovani i mogu se dinamički koristiti. To omogućava konvergenciju fiksnih, mobilnih, broadband i broadcast servisa. Korisnici traže objedinjeni pristup, široku paletu usluga, ne žele da budu svesni postojanja fiksne ili bežične mreže.

Za unapređenje mobilnih servisa koje nudi 5G, podrška Cloud servisa je od velike važnosti. Dostizanje malih nivoa kašnjenja sigurno neće biti moguće bez instaliranja velikog broja čvorišta (POP, Point of Presence) i bez primene Cloud tehnologije u obodnom (edge) delu mreže (tzv. Mobile Edge Computing), a ni pristup podacima, softveru i servisima sa bilo kog mesta u bilo koje vreme. Servisi bazirani na Cloudu koriste uskladištene podatke i fajlove velikog kapaciteta (npr. slike visoke rezolucije, video fajlovi), zato su primena $5 \mathrm{G}$ i unapređenje mobilne mreže praktično neodvojivi od Cloud computing-a [2]. 5G mreža predstavlja spregu različitih naprednih tehnologija 
kao što su Software Defined Networking (SDN), Network Function Virtualization (NFV), Mobile Edge Computing (MEC), Fog Computing (FC) i biće sposobna da podrži različite pristupne tehnologije.

Unaprediti mrežu i zadovoljiti zahteve za kapacitetom uvek je veliki izazov za mobilne operatere. Povećana gustina mreže, koju zahteva 5G, komplikuje i izgradnju i upravljanje mreže. Prenos signala na višim frekvencijama je osetljiv i to poskupljuje opremu. Stoga je neophodno poboljšati korišćenje frekventnih opsega višetrukim korišćenjem frekvencija, koristiti veće frekventne opsege za prenos (bandwith) i poboljšati spektralnu efikasnost MIMO antenama (MIMO - Multiple In Multiple Out).

\section{SPEKTAR KAO VITALNI RESURS}

Međunarodne telekomunikacione organizacije još uvek rade na preciziranju i definisanju opsega koji će se komercijalno koristiti. Da bi se osiguralo investiranje u $5 \mathrm{G}$ tehnologiju potrebno je obezbediti dodatne resurse u spektru, od nekoliko stotina $\mathrm{MHz}$ do nekoliko $\mathrm{GHz}$ po operateru. Pritom je najvažnije voditi računa o interferenciji. Za dugoročne investicije neophodna je stabilnost $\mathrm{u}$ regulatornoj politici i predvidivo upravljanje spektrom. Potrebno je i praćenje istraživanja i novih tehnika prenosa signala. Spektar je resurs koji svaka država prodaje, odnosno iznajmljuje na određeni rok. Prodaja spektra kao resursa obezbeđuje državi sredstva koja se mogu iskoristiti za unapređenje uslova za život njenih građana i drugu opštu dobrobit zajednice. Radio-spektar je sve skuplji i na poslednjoj aukciji u SAD od prodaje spektra prikupljeno je \$45 milijarde. Vrednost spektra zavisi od mnogih faktora. Nije jednaka i jedinstvena, razlikuje se od tržišta do tržišta. Različiti korisnici spektra različito vrednuju pojedine opsege, zavisno od svoje strategije, primenjene tehnologije, konkurentskih uslova, projekcije prihoda.

Razmatra se korišćenje frekventnih opsega i iznad 6 GHz. Centimetarski (cmWave, $6 \mathrm{GHz}-30 \mathrm{GHz}$ ) i milimetarski talasi (mmWave, 30-100 GHz) pogodni su za pristupnu mrežu velike gustine i za dostizanje velikih brzina protoka. Kompanija Samsung je još 2013. godine ostvarila prvi 5G komunikacioni link na frekvenciji 28 $\mathrm{GHz}$ uz maksimalnu bitsku brzinu od 1,056 Gbps na rastojanju do $2 \mathrm{~km}$ pomoću antene sa 64 elementa. $\mathrm{U}$ opsegu od interesa za 5G (20-100 GHz) može se ponuditi između nekoliko kontinuiranih frekventnih opsega (kanala) od 1-10 GHz. Na Slici 2 prikazani su segmenti spektra namenjeni raspodeli (zatamnjeno) i potencijalni segmenti za raspodelu (šrafirano) na konferenciji WRC-19 (World Radio Conference 2019. godine), međunarodne organizacije za telekomunikacije ITU. Idealno je obezbediti ukupnu širinu kanala do $1 \mathrm{GHz}$ za svakog operatera. Zbog toga $5 \mathrm{G}$ tehnologija, u odnosu na $4 \mathrm{G}$, realno može ponuditi 10 i više puta veće brzine, više od 10 Gbps. Radi što efikasnijeg i ekonomičnijeg korišćenja spectra, primenjivaće se tehnike koordiniranog deljenog pristupa (Coordinated Shared Access), dinamičke preraspodele spektra (Dinamic Spectrum Allocation) i agregacije nosilaca (Carrier Aggregation). Spektralna efikasnost 5G može se unaprediti i masovnom primenom MIMO anatena $\mathrm{i}$ tehnikom usmerenog emitovanja (beam-forming). Spektar ostaje izazov za implementaciju 5G.

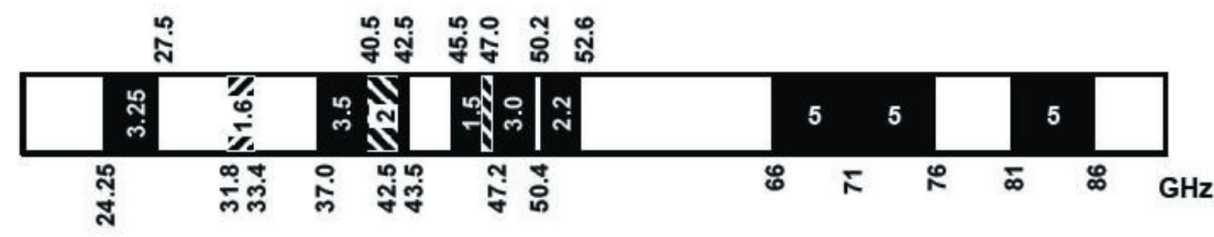

In scope of WRC-19, allocated to Mobile Service already

In scope of WRC-19, may require allocation to Mobile Service

Slika 2. Raspodela spektra za 5G iznad 6 GHz (Global mobile Suppliers Association 2016).

\section{ANALIZA UTICAJA NA EKONOMSKI RAST I RAZVOJ}

Iz ekonomske perspektive, najveći uticaj imaće investicije u $5 \mathrm{G}$ tehnologiju i povećanje efikasnosti i produktivnosti usled primene $5 \mathrm{G}$ tehnologije. Tehnološka unapređenja 5G (veće brzine prenosa, veći kapacitet, malo kašnjenje) omogućiće povećanje produktivnosti, unapređenje poslovnih procesa i konkurentnosti, nove, efikasnije biznis modele i nove servise sa dodatnom vrednošću. Investicije i rast produktivnosti uticaće na otvaranje novih radnih mesta i povećanje zarada. Prethodne generacije mobilnih tehnologija već su izmenile način na koji ljudi komuniciraju. 5G tehnologija promeniće način na koji mnoge privredne grane funkcionišu. 
Ključni uticaj na društvo, 5G će ostvariti kroz unapređeno mobile broadband iskustvo. Za to je potrebna odlična pokrivenost terena, naročito unutrašnjosti objekata i veliki kapacitet mreže, koja mora biti sposobna da opsluži veliki broj uređaja sa velikim brzinama protoka podataka. Efikasnost takve mreže ogleda se kroz energetsku efikasnost i efikasnost prenosa (lower cost-per-bit). Sa razvojem mobilnog broadband, koji nudi 5G mreža, i identifikovanjem prednosti koje pruža, rašće zahtevi privrede i biznisa za njim. Te prednosti su smanjenje troškova, povećanje prodaje, pristup novim tržištima i novim korisnicima, ušteda vremena zaposlenih, bolji kvalitet usluge.

Nove investicije, R\&D i tehnološke inovacije imaće veliki efekat na rast globalne ekonomije u narednih dvadesetak godina. Istraživanje kompanije IHS Markit pokazuje da će do 2035. godine 5G tehnologija omogućiti \$12,3 hiljade milijardi (trilion \$) ekonomskog obrta, što je jednako potrošnji na celom SAD tržištu u 2016. godini [3]. Uvođenje $5 \mathrm{G}$ tehnologije omogućiće otvaranje 22 miliona novih radnih mesta [3]. U izgradnju infrastrukture 5G mreže i razvoj novih aplikacija godišnje će se investirati prosečno oko $\$ 200$ milijardi (biliona). 5G će time uticati na dugoročni rast svetskog BDP. IHS Markit još kaže da će od 2020-2035. ukupan doprinos razvoja 5G na svetsku ekonomiju biti jednak vrednosti BDP današnje Indije, koja je sedma najveća ekonomija u svetu.

Ukupan godišnji BDP Evrope danas iznosi 660 milijardi $€$, a IT sektor u njemu učestvuje sa 5\% [4]. Prema izveštaju Svetske banke, dodatna ulaganja u ICT uticala bi na rast u visokoprofitnim granama za $1,21 \%$, a u srednje i niskoprofitnim granama privrede za 1,38\% [4]. Izgradnja nove $5 \mathrm{G}$ mrežne infrastrukture prilika je za nova istraživanja, integraciju i proizvodnju, saradnju istraživačkih centara, univerziteta $\mathrm{i}$ industrije, naročito prilika za mala i srednja preduzeća da u konkurentnom okruženju učestvuju u implementaciji i širokoj primeni $5 \mathrm{G}$ mreže i njenih servisa. Prema podacima UMTS Foruma, konektivnost na bežičnu mrežu biće povećana sa 45\% u 2012. godini na 75\% u 2020. godini, kada će WiFi pokrivenost iznositi 50\% ukupne pokrivenosti [4]. Svedoci smo stalnog porasta broja različitih mobilnih uređaja i eksponencijalnog rasta mobilnog saobraćaja (CAGR 50-60\%) u kome dominira video-saobraćaj. Heterogene mobilne mreže postaju sve kompleksnije i troše sve više energije. Neophodan je njihov održiv rast i razvoj, fleksibilnost i skalabilnost, što nudi i omogućava 5G mreža.

Prema studiji za potrebe Evropske komisije, ulaganje u 5G donelo bi sredinom narednog desetleća oko $113 \mathrm{mi}$ lijardi evra potencijalnih društveno-ekonomskih benefita u zemljama EU, zbirno u raznim oblastima a najviše u generisanju oko 2 miliona novih radnih mesta (Slika 3) [5]. Procenjuje se da bi čak 63\% svih benefita proisteklo od korišćenja $5 \mathrm{G}$ servisa od strane poslovnih korisnika (preduzeća). Prema istoj studiji, troškovi uvođenja $5 \mathrm{G} \mathrm{u}$ 28 zemalja EU do 2020. mogli bi dostići i do 56 milijardi evra [5]. Na osnovu istraživanja kompanije ABI Research, očekuje se da do 2025. godine godišnji prihodi mobilnih operatera od $5 \mathrm{G}$ tehnologije globalno dostignu do oko 225 milijarde evra [6]. Britanski mobilni operater O2 Telefonica UK očekuje da će do 2026. godine 5G ostvariti veće ekonomske efekte nego tehnologija optika do kuće (Fiber-to-the-home, FTTH), i to 18,5 miliona GBP naspram 17,5 miliona GBP od FTTH [7]. Ti efekti će poticati od izgradnje infrastrukture, javnih servisa, povećanja produktivnosti i unapređenja lanaca snabdevanja. Praktično, ovo ekonomski znači da 5G ima brži povrat investicija (ROI) u odnosu na FTTH.

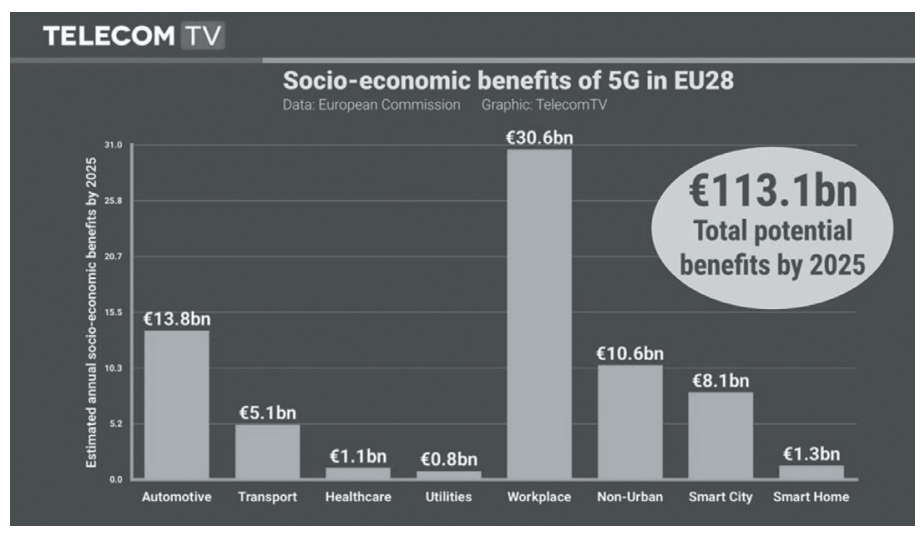

Slika 3. Društveno-ekonomski benefiti 5G u EU28

(http://www.5gensure.eu/news/insights-socio-economic-impact-5g). 
Lanac vrednosti 5G (value chain) uključuje različite tehnološke kompanije: mrežne operatere, provajdere mrežnih platformi, proizvođače mrežne opreme i komponenata, proizvođače uređaja, developere aplikacija i sadržaja. Veliki propusni opseg je prilika da medijske kuće i filmska industrija mogu da strimuju sadržaje sa što većom rezolucijom i time gledaocima pruže jedinstveno iskustvo i kvalitet. Industrija onlajn igara ima problem sa kašnjenjem u mreži i zbog toga igrači nemaju veliki komfor u igranju preko interneta. Rešenje je u $5 \mathrm{G}$ standardu.

5G tehnologija imaće veliki uticaj na transformaciju lokalne ekonomije i na upravljanje gradskom infrastrukturom (Smart Cities projekti). Kroz upravljanje gradskim saobraćajem i javnom rasvetom već je moguće ostvariti značajne uštede u potrošnji električne energije, goriva $\mathrm{i}$ vremena koje se troši u saobraćajnim gužvama, zastojima, nalaženju parking mesta. čime se smanjuje i emisija štetnih gasova u atmosferu. Tu su i senzori potrošnje vode i energije, kamere i dronovi za nadzorom okoline i infrastrukture radi unapređenja sistema javne bezbednosti i efikasnog korišćenja resursa.

Za implementaciju 5G mreže u gradovima neophodno je 10-100 puta više lokacija za antene nego za 3G i 4G. Veličina ćelija smanjena je jer se mora povećati kapacitet mreže i brzina protoka. Broj uređaja koji će biti povezan na 5G mrežu mnogo je veći nego danas. Od robusnosti 5G mreže zavisi ekonomska korist i ušteda koja će se ostvariti kroz realizaciju projekata Smart Cities.

Implementacijom 5G mreža više neće biti potrebno realizovati posebne senzorske mreže za povezivanje velikog broja senzora, aktuatora, informacionih tabli (mission critical services). 5G ispunjava sve uslove za tehničke i poslovne inovacije, nova mrežna rešenja i njihovu primenu na tzv. vertikalnom tržištu: u industriji, auto-industriji, energetici, poljoprivredi, saobraćaju, bankarstvu, zdravstvu, obrazovanju i drugim privrednim granama.

\section{INTERNET OF THINGS}

Do 2022. biće preko 30 milijardi pametnih uređaja na planeti [8]. 5G će omogućiti njihovu praktično neograničenu međusobnu komunikaciju. Kombinacija pametnih uređaja, mobilne tehnologije i Cloud computinga omogući će novo iskustvo korisnika, nove usluge i nove aplikacije, kao što su vozilo bez vozača (autonomno vozilo) sa ugrađenim automatskim rutiranjem u saobraćaju, pametna gradska infrastruktura (parking, lighting), unapređena realnost (augmented reality) i slično (Slika 4).

$5 \mathrm{G}$ tehnologija ključna je za implementaciju masovnog Internet of Things, jer podržava povezivanje po principu „bilo gde, bilo kad, bilo ko i bilo šta”. Ovo je bazično za dobre prihode u skladu sa ekonomijom obima (economy of scale).

IoT kompanije nemaju veliku potrebu za većim brzinama prenosa za svoje aplikacije, ali bi im svakako bilo od koristi da njihovi senzori mogu da rade nekoliko godina sa istom baterijom, bez zamene. To će omogućiti 5G tehnologija, koja kao jedan od ciljeva ima nisku potrošnju uređaja i desetogodišnji radni vek baterija. IoT aparati će sigurno postati novi generator prihoda za kompanije koje će ih proizvoditi.

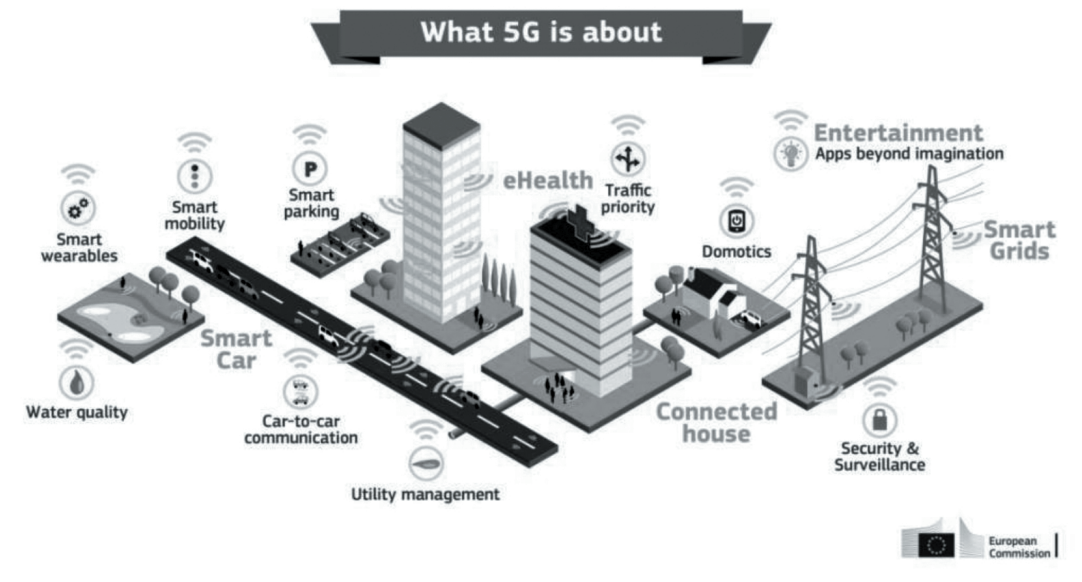

Slika 3. Društveno-ekonomski benefiti 5G u EU28

(http://www.5gensure.eu/news/insights-socio-economic-impact-5g). 
Među najvažnije aplikacije masovnog IoT spadaju one namenjene poljoprivredi i šumarstvu: monitoring poljoprivrednog zemljišta (dronovi sa kamerama i senzori), upravljanje sistemima za navodnjavanje, nadzor i dojava požara.

\section{REALNOST $5 G$}

Poznato je da se danas 70-80\% svih mobilnih konekcija obavlja iz kancelarija i domova (indoor), gde je osim mobilnog prisutan i fiksni broadband (ADSL/VDSL/ FTTH ruteri sa WiFi pristupom) [8]. Velika konkurencija 5G tehnologiji je već masovni WiFi, koji današnji smartfon korisnici uglavnom koriste za pozive (aplikacija Viber) i prenos podataka. Ova činjenica nagoni na razmišljanje: da li će korisnici sa navikom besplatnog WiFi pristupa ikada više imati potrebu za mobilnim pristupom, ma koliko on bio brz (kao što jeste u slučaju $5 \mathrm{G}$ ).

Za novu mrežu i infrastrukturu potrebna su nova ulaganja, a prihodi opratora već duži niz godina ne rastu. Pitanje je hoće li svi mobilni operateri izdržati trku ili će biti prinuđeni da se integrišu sa većim, bogatijim i moćnijim (globalnim) operaterima. Da li je koncentracija neizbežna i da li će mnoge zemlje ostati sa samo jednim mobilnim operaterom, kao što neretko imaju jednog snabdevača vodom ili strujom? Uostalom, na početku ovog rada napomenuli smo da $5 \mathrm{G}$ ima karakter tehnologije opšte namene koja postaje nezaobilazni deo svakodnevnog života.

\section{ZAKLJUČAK}

Očekuje se da će uvođenje 5G tehnologije imati značajne ekonomske efekte, pre svega kroz povećanje produktivnosti. $5 \mathrm{G}$ mreža treba da ponudi kapacitet i brzine dovoljne za prenos (upload i download) zahtevnih visokokvalitetnih video-servisa bežičnim putem, ali i povezivanje velikog broja uređaja sa bilo kog mesta u bilo koje vreme. Prednosti uvođenja 5G tehnologije su izazovne i velike, a mogućnosti za inovacije raznovrsne. Da bi se ostvarili maksimalni benefiti za različite stejkholdere, potrebno je blagovremeno obaviti preraspodelu resursa u spektru i voditi računa o regulaciji tržišta. $5 \mathrm{G}$ će omogućiti transformaciju industrije, nove biznis modele, nove aplikacije, nove izvore prihoda i nova radna mesta.

\section{LITERATURA}

[1] 5G Radio Access, Ericsson White Paper, Uen 284 23-3204 Rev C | April 2016.

[2] 4G Americas, 4G Americas' recommendations on $5 \mathrm{G}$ requirements and solutions, October 2014. (dostupno na http://www.5gamericas. org/files/2714/1471/2645/4G_Americas_Recom mendations_on_5G_Requirements_and_ Solutions_10_14_2014-FINALx.pdf, pristup dana 11.03.2017)

[3] IHS Economics \& IHS Technology, The 5G Economy - How 5G technology will contribute to the global economy, January 2017. (dostupno na https://www.qualcomm.com/media/documents/files/ ihs- 5g-economic-impact-study.pdf, pristup dana 11.03.2017)

[4] 5G PPP \& European Commission brochure, 5G vision, (dostupno na https://5g-ppp.eu/wp-content/ uploads/2015/02/5G-Vision-Brochure-v1.pdf, pristup dana 11.03.2017)

[5] European Commission Study, Identification and quantification of key socio-economic data to support strategic planning for the introduction of $5 \mathrm{G}$ in Europe, (dostupno na https://ec.europa.eu/digital-single-market/en/news/5g-deployment-couldbring-millions-jobs-and-billions- euros-benefitsstudy-finds, pristup dana 11.03.2017)

[6] https://www.abiresearch.com/press/abi-researchprojects-5g-worldwide- service-revenue/ , pristup dana 11.03.2017.

[7] http://news.o2.co.uk/?press-release=uk-5g-infrastructure-outstrip- economic-benefits-fibre-broadband-2026, pristup dana 11.03.2017.

[8] Ericsson mobility report, November 2016 (dostupno na https://www.ericsson.com/mobility-report, dana 11.03.2017) 


\title{
THEANALYSIS OF THE ECONOMICASPECTS OF 5G TECHNOLOGY IMPLEMENTATION
}

\begin{abstract}
:
$5 \mathrm{G}$ is the next step in the evolution of mobile technologies. Compared to the previous generation of mobile technology, $5 \mathrm{G}$ is significantly different due to a small delay (near zero latency) and higher speed transfer from 1 to $10 \mathrm{Gbps}$. The impact of $5 \mathrm{G}$ technologies on the economy has a simple flow: investing in the development and implementation of $5 \mathrm{G}$ networks, investments create new jobs and all of this together increases the GDP (Gross Domestic Product). Also, we will have the benefits of new technologies, increase productivity and efficiency due to the ubiquitous ultra-fast broadband, savings in time and resources by using advanced $5 \mathrm{G}$ services. In the future, $5 \mathrm{G}$ technology will be the basis for innovation in the economy and industry. In this paper, the analysis of impact of $5 \mathrm{G}$ technology deployment on the economy is given.
\end{abstract}

Keywords:

Spectrum, IoT, Cloud, 5G Services, MIMO. 